\title{
In Vitro Antioxidant and Antibacterial Activities of Quinoa Flavonoids Extracted by Ethanol-Ammonium Sulfate Aqueous Two-Phase System
}

\author{
Xiaoyong Wu, Enze Liu, Changying Liu, Yan Wan, Qi Wu, Dabing Xiang and Yanxia Sun * \\ Key Laboratory of Coarse Cereal Processing, Ministry of Agriculture and Rural Affairs, Chengdu University, Chengdu \\ 610106, China \\ *For correspondence: sunyanxia1976@cdu.edu.cn \\ Received 09 December 2020; Accepted 25 February 2021; Published 10 May 2021
}

\begin{abstract}
Quinoa (Chenopodium quinoa Willd.) is a functional and ideal food for human nutrition and an Andean seed-producing crop. In this study, ultrasonic-assisted extraction of total flavonoids in Quinoa with ethanol $\left(\mathrm{C}_{2} \mathrm{H}_{5} \mathrm{OH}\right)$-ammonium sulfate $\left(\left(\mathrm{NH}_{4}\right)_{2} \mathrm{SO}_{4}\right)$ aqueous two-phase system was performed based on the Box-Behnken experimental design principle. The highest extraction rate of TFQ under the condition of $28 \% \mathrm{C}_{2} \mathrm{H}_{5} \mathrm{OH}-14 \%\left(\mathrm{NH}_{4}\right)_{2} \mathrm{SO}_{4}$ aqueous two-phase extraction system was used to analyze the variance of TFQ extraction rate as the response value. The multiple quadratic linear regression equation was obtained by a three-factor three-level response surface method. The extraction rate $=74.28+1.78 \mathrm{~A}+0.10 \mathrm{~B}+0.38 \mathrm{C}+0.20$ $\mathrm{AB}+0.05 \mathrm{AC}+0.05 \mathrm{BC}+1.000 \mathrm{E}-002 \mathrm{~A}^{2}-0.94 \mathrm{~B}^{2}-0.69 \mathrm{C}^{2}$. The response surface analysis showed that the best extraction conditions of aqueous two-phase were the crude TFQ mass fraction $20.6 \%, \mathrm{pH} 7.18, \mathrm{NaCl}$ mass fraction $2.23 \%$ and the maximum value predicted by the extraction rate model was $75.9293 \%(P=0.994)$. The average extraction rate of TFQ was $75.3 \%$, according to the optimal two-aqueous phase extraction conditions. The ETFQ has varying degree of scavenging effect on hydroxyl radical, oxygen free radicals, nitrite and $\cdot \mathrm{ABTS}^{+}$compared with vitamin $\mathrm{C}$. Among them, the scavenging effect of the ETFQ on hydroxyl radical, oxygen free radicals and $\cdot \mathrm{ABTS}^{+}$was greater than vitamin $\mathrm{C}$, except nitrite. Also, the ETFQ has the strongest inhibitory effect on E. coli and Bacillus subtilis, and the inhibitory rate can reach up to high dose 97.59 and $98.44 \%$, MIC is $1.56 \mathrm{mg} / \mathrm{mL}$; the second is the inhibition of S. aureus, MIC is $6.25 \mathrm{mg} / \mathrm{mL}$. It has the weakest inhibitory effect on Salmonella. The antibacterial rate was positively correlated with the ETFQ mass concentration. The results help to discover the medicinal effects of quinoa in addition to nutrition to carry out more in-depth research and increase economic value. (C) 2021 Friends Science Publishers
\end{abstract}

Keywords: Quinoa flavonoids; Antioxidant activity; Antibacterial; Aqueous two-phase extraction

\section{Introduction}

Quinoa (Chenopodium quinoa Willd.) is a functional and ideal food grown in the Andean highlands. It has attracted interest in the scientific community due to its good nutritional value (Dini et al. 2010; Navruz-Varli and Sanlier 2016; Vilcacundo and Hernández-Ledesma 2017). European and North American consumers are increasingly aware of the exceptional nutritional qualities of quinoa seeds and sprouts, are now considered "functional foods" (Angeli et al. 2020). There is extensive literature on the chemical composition of quinoa seed, which cover all nutritional aspects such as chemical characterization of proteins (Dakhili et al. 2019; Sezgin and Sanlier 2019). As a new high-nutrient coarse grain, quinoa is also rich in flavonoids compared to corn, rice and wheat (Dini et al. 2010; Carciochi et al. 2015; Lopez et al. 2018). The study showed that the contents of quercetin and kaempferol in quinoa were much higher than those in buckwheat (there was no kaempferol in buckwheat) (Zhu 2018; Xiang et al. 2019b).

Quinoa contains natural phytoestrogens, one of the flavonoids, especially seeds with colored testa. Flavonoids are a group of phenolic compounds with 2-phenyl-1,4benzopyrone backbone and divided into subgroups as flavones, isoflavones, flavan, roanthocyanidins, and anthocyanidins. Flavonoids such as quercetin and epicatechin exhibit antioxidant activity (Penido et al. 2017; Rai et al. 2018; Xiang et al. 2019a) and has a negative correlation with the risk of developing coronary heart disease (Bohn et al. 2012; Sanchez Hernandez et al. 2016) and type II diabetes mellitus (Abe et al. 2017). Flavonoids may significantly improve the cognitive ability of patients in acute and chronic diseases. Evidence indicates that flavonoids have the potential to reduce the risk of cervical cancer, lung cancer, leukemia, breast cancer, colorectal cancer and prostate cancer (Brend et al. 2012;

To cite this paper: Wu X, E Liu, C Liu, Y Wan, Q Wu, D Xiang, Y Sun (2021). In vitro antioxidant and antibacterial activities of quinoa flavonoids extracted by ethanol-ammonium sulfate aqueous two-phase system. Intl J Agric Biol 25:1187-1196 
Orfali et al. 2016; Filho et al. 2017; Sezgin and Sanlier 2019). Flavonoids have strong antioxidant effects, can eliminate harmful superoxide radical groups in the human body and have physiological activities such as anti-aging, enhancing immunity and so on (Perez Vizcaino and Fraga 2018, Abotaleb et al. 2019; Lavanya et al. 2019; Romano et al. 2020). As a result, more and more researchers are turning their attention to the active components of quinoa.

Aqueous two-phase extraction (ATPE) technology is an effective separation technology widely used in natural product separation, biological extraction, pharmaceuticals, food chemical industry and other fields (Gu and Glatz 2007; Lee et al. 2017; Assis et al. 2020; Huang et al. 2020). Compared with traditional liquid-liquid extraction, an aqueous two-phase system is a milder extraction and separation technology that is non-toxic, non-flammable, low cost and not prone to emulsion. In recent years, watersoluble low-grade alcohols and salts aqueous two-phase system has overcome the problems of high cost, low efficiency and difficulty in target recovery and treatment of traditional two-phase technology. It is easy to integrate with other technologies and has attracted much attention. Aqueous two-phase extraction has been successfully applied as gentle unit operation for the purification of biomolecules such as therapeutic proteins, enzymes, and antibiotics (Garai and Kuma 2013; Shkinev et al. 2013). At present, there is very little information about the optimization of the extraction process of total flavonoids from quinoa. The purpose of this experiment is to study the extraction conditions of total flavonoids from quinoa by ultrasonicassisted two-phase extraction technology. The optimal combination of extraction conditions is analyzed by response surface methodology, and then the antimicrobial activity of extracted TFQ (ETFQ) was analyzed.

In recent years, the planting area of quinoa has increased every year, but the processing is still in the relatively primitive stage, and the economic value is not very high (Ruiz et al. 2014; Bellemare et al. 2018). Here, we provide a theoretical basis for the in-depth development of quinoa, including its medicinal value, thereby increasing its economic value.

\section{Materials and Methods}

\section{Material and strains}

Mature quinoa seeds (CD-1, black) were collected from Yanyuan County, Liangshan Prefecture, Sichuan Province, China. The seeds were cleaned and dried. The dried seeds were ground and the powder was obtained through 100mesh sieve.

The test strains were E. coli ACCC11864, Salmonella. ACCC 01319, S. aureus ACCC 01332, Bacillus subtilis ACCC01430, provided by professor Jianglin Zhao and Sichuan Industrial Institute of Antibiotics of Chengdu University (SIIAC).

\section{Reagents and instruments}

Anhydrous ethanol, sodium nitrate, aluminum nitrate, and sodium hydroxide were supplied by Merck (Darmstadt, Germany). MH and LB medium, and a Mackinot's turbidimeter were purchased from Solarbio. All reagents were of analytical grade. A small automatic crusher (Nanjing, China), Rotary evaporator (Yarong, Shanghai), LDZM-40KCM Autoclave (SHENAN, Shanghai), HZQ-C constant temperature incubator (Aohua, Changzhou) and Multimode reader (potenov, Beijing) were also used in the experiments.

\section{Methods}

TFQ extraction and quantitative determination: Ten grams of defatted quinoa powder was dispersed in $50 \mathrm{~mL}$ $75 \%$ ethanol, followed by ultrasonic extraction for $30 \mathrm{~min}$. The extract was obtained by centrifugation at $5500 \mathrm{r} / \mathrm{min}$ (Hemalatha et al. 2016). The three times extract was combined and concentrated into the aqueous phase by vacuum filtration and rotary evaporation. The crude TFQ content was determined by $\mathrm{NaNO}_{2}-\mathrm{Al}\left(\mathrm{NO}_{3}\right)_{3}$ colorimetry according to the results of rutin standard curve $\mathrm{Y}=0.0897 \mathrm{X}$ $+0.0005\left(R^{2}=0.9993\right)$.

Establishment of ethanol-ammonium sulfate aqueous two-phase system: The extraction ability of ethanol and ammonium sulfate aqueous two-phase system for TFQ extracts with certain mass concentration was investigated. Ethanol and ammonium sulfate were prepared to form a stable two-phase system. Crude TFQ were added to the system. The system was fully mixed by oscillation. After centrifugation, samples were taken from the upper and lower phases and the absorbance were determined by the method mentioned above using the multimode reader. The mass concentration of TFQ in the upper and lower phases was calculated according to the standard curve. The partition coefficient $(K)$ and extraction rate $(Y)$ of the system were calculated according to the formulas (1) and (2).

$$
\begin{gathered}
K=\frac{v_{t}}{V_{h}} \\
=\frac{v_{t} c_{t}}{Y_{t} c_{\mathrm{t}}+v_{h} c_{h}} x 100 \%
\end{gathered}
$$

In formulas (1) and (2), $V t$ and $V b$ are the upper and lower phase volumes (mL); $C t$ and $C b$ were the mass concentration of TFQ in upper and lower phases $(\mathrm{mg} / \mathrm{mL})$. $Y t$ were the TFQ extraction rate in upper phases.

Optimize design the response surface experiments: After determining the optimal two-phase composition of $\mathrm{C}_{2} \mathrm{H}_{5} \mathrm{OH}-\left(\mathrm{NH}_{4}\right)_{2} \mathrm{SO}_{4}$ aqueous two-phase system, the effects of the flavonoids crude extract mass fraction, $\mathrm{pH}$ and $\mathrm{NaCl}$ concentration on TFQ extraction rate were studied. According to the single factor test results, 17 response tests with three factors and three levels were designed by 
Design-Expert 8.0 to analyze the optimum technological conditions of TFQ two-phase extraction.

After obtaining the optimal aqueous two-phase system for extract TFQ, the system was amplified to extract quinoa flavonoids, and the ETFQ were concentrated and lyophilized for subsequent experiments.

\section{In vitro antioxidant activity}

Scavenging of hydroxyl radical: One milliliter of 1.5 mmoL /L 1,10-phenanthroline ethanol solution was added to a $10-\mathrm{mL}$ colorimetric tube. Then $2.0 \mathrm{~mL}$ of phosphate buffer, $1.0 \mathrm{~mL} \mathrm{H}_{2} \mathrm{O}$ and $1.0 \mathrm{~mL}$ of $0.75 \mathrm{mmoL} / \mathrm{L}$ ferrous sulphate solution $\left(\mathrm{FeSO}_{4}\right)$ were added into the tube in turn. The solutions were fully mixed and $1.0 \mathrm{~mL}$ of $0.1 \% \mathrm{H}_{2} \mathrm{O}_{2}$ was added. All the components were mixed and kept at $37^{\circ} \mathrm{C}$ for $60 \mathrm{~min}$. The absorbance of the mixture was measured at $536 \mathrm{~nm}\left(\mathrm{~A}_{0}\right)$. All other conditions were held constant. The water from the tube was replaced with the different concentrations of ETFQ solution, and the absorbance was measured at $536 \mathrm{~nm}\left(\mathrm{~A}_{1}\right) .0 .1 \% \mathrm{H}_{2} \mathrm{O}_{2}$ was replaced by $\mathrm{H}_{2} \mathrm{O}$ to get an $\mathrm{A}_{2}$ under the same conditions. The clearance ability was calculated according to the following formula (3):

$$
\text { - } O H \text { clearance ability }=\frac{A_{1}-A_{0}}{A_{m}-A_{n}} \times 100 \%
$$

Scavenging of oxygen free radicals: Three milliliters of Tris- $\mathrm{HCl}$ buffer $(50 \mathrm{mmol} / \mathrm{L}, \mathrm{pH} 8.2)$ were placed in $10-\mathrm{mL}$ test tube separately and preheated in $25^{\circ} \mathrm{C}$ water bath for 20 min. $0.5 \mathrm{~mL}$ of different concentrations of ETFQ and 2.0 $\mathrm{mL}$ of pyrogallol solution $(30 \mathrm{mmol} / \mathrm{L})$ was added respectively, the reaction mixture was mixed well and incubated for $8 \mathrm{~min}$ at $25^{\circ} \mathrm{C}$. $1.0 \mathrm{~mL} \mathrm{HCl}$ solution $(10$ $\mathrm{mmol} / \mathrm{L}$ ) was added to stop the reaction, and the absorbance $\mathrm{A}_{1}$ was measured at $320 \mathrm{~nm}$ with buffer solution as blank. Other conditions remained unchanged, the absorbance was measured at $320 \mathrm{~nm}$ with distilled water instead of pyrogallol solution $\left(\mathrm{A}_{2}\right)$ and with distilled water instead of the ETFQ solution $\left(\mathrm{A}_{3}\right)$. The clearance ability was calculated according to the following formula:

$\mathrm{O}^{2-\bullet}$ clearance ability $=\frac{A_{32}-A_{1}+A_{2}}{A_{7}} \times 100 \%$

Scavenging of nitrite: To determine the nitrite scavenging ability, 0.2, 0.4, 0.6, 0.8, 1.0 and $1.2 \mathrm{~mL}$ of ETFQ solution $(1.0 \mathrm{~g} / \mathrm{L})$ was respectively absorbed and placed in $10 \mathrm{~mL}$ test tube. To the tube, $2.5 \mathrm{~mL}$ of $10 \mathrm{mg} / \mathrm{L} \mathrm{NaNO}_{2}$ were added respectively, and the reaction took place in a water bath at $37^{\circ} \mathrm{C}$ for $30 \mathrm{~min}$. After reaction completion, $0.5 \mathrm{~mL}$ of $0.4 \%$ p-aminobenzenesulfonic acid solution and $0.25 \mathrm{~mL}$ $0.2 \%$ naphthalene hydrochloride was added and mixed well. Seven milliliters of distilled water were added, mixed well, and allowed to stand for $15 \mathrm{~min}$. The $\mathrm{A}_{1}$ was measured at $538 \mathrm{~nm}$ with $50 \%$ ethanol as a blank. The $\mathrm{A}_{0}$ was determined at $538 \mathrm{~nm}$ without the addition of the ETFQ under the same conditions. Among them, the background value of the ETFQ was $\mathrm{A}_{\mathrm{i}}$. The clearance ability was calculated according to the following formula:

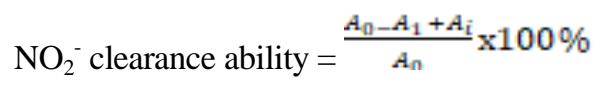

Scavenging of $\mathrm{ABTS}^{+}$: $\cdot \mathrm{ABTS}^{+}$was generated by the reaction of a $7 \mathrm{~m} M$ ABTS aqueous solution with a $2.4 \mathrm{~m} M$ $\mathrm{K}_{2} \mathrm{~S}_{2} \mathrm{O}_{8}$ aqueous solution in molar equivalents, and the mixture was incubated in the dark at $23^{\circ} \mathrm{C}$ for $12-16 \mathrm{~h}$. The solution was then diluted with ethanol to acquire an absorbance of $0.7 \pm 0.02$ at $734 \mathrm{~nm}\left(\mathrm{~A}_{0}\right)$. Next, 0.02, 0.04, $0.06,0.08,0.10$ and $0.12 \mathrm{~g} / \mathrm{L}$ of ETFQ were absorbed and placed in a $10-\mathrm{mL}$ test tube. Then $3.9 \mathrm{~mL}$ of the abovementioned solution was added, and the reaction took place at $23^{\circ} \mathrm{C}$ in the dark for $6 \mathrm{~min}$. The absorbance at 734 nm (A) was measured with distilled water as a blank. The clearance ability was calculated according to the following formula:

$\mathrm{ABTS}^{+}$clearance ability $=\frac{A_{0}-A}{A_{0}} \times 100 \%$

Determination of minimum inhibitory concentration (MIC) and minimum bactericidal concentration (MBC) of ETFQ

According to the types of test bacteria, the sterilized test tubes were divided into four groups, 12 in each group under sterile conditions. In the first test tube, two milliliters of LB liquid medium with two times mass concentration were added. Two milliliters of LB liquid medium were added to the 2-10 test tubes, respectively. Two milliliters of ETFQ were added to the first test tube. According to the double dilution method, the ETFQ mass concentration of each tube was $50,25,12.5,6.25,3.12,1.56,0.78,0.39,0.195$ and 0.00 $\mathrm{mg} / \mathrm{mL}$, respectively. Then $0.1 \mathrm{~mL}$ suspension of each strain, which were diluted to $0.5 \mathrm{McF}$ arland turbidity, were added to the 10 test tubes. The $11^{\text {th }}$ tube was used as the positive control, and only $2 \mathrm{~mL}$ of medium LB were added. The $12^{\text {th }}$ tube was used as a negative control and $1 \mathrm{~mL}$ of medium LB with two times mass concentration and $1 \mathrm{~mL}$ ETFQ were added. The abovementioned test tubes were cultured in a constant temperature incubator at $37^{\circ} \mathrm{C}$ for 24 h. From each of the 12 test tubes, $0.1 \mathrm{~mL}$ was taken and the aliquots were spread on the solid LB medium plate and cultured in a constant temperature incubator at $37^{\circ} \mathrm{C}$. The concentration of ETFQ with bacterial free in $24 \mathrm{~h}$ was determined as the MIC, and that in $48 \mathrm{~h}$ was the MBC.

\section{Determination of bacteriostatic rate of ETFQ}

The Oxford cup plate assay was used to detect the bacteriostatic rate of ETFQ (Shi et al. 2011). The doublelayer medium was prepared. Four Oxford cups were placed 
in the cooled lower layer, then the upper layer medium (MH) with tested strains, which was diluted to $1 \mathrm{McFarland}$ turbidity standard with physiological saline, was added. Four holes were formed after the medium was cooled. To the four pores, $200 \mathrm{uL}$ of different concentrations ETFQ solution and $0.5 \%$ potassium sorbate (positive control) were added. ETFQ were tested at low, medium and high doses, respectively. The dishes were sealed and cultured in a constant temperature incubator at $37^{\circ} \mathrm{C}$ for $12 \mathrm{~h}$. The diameter of the bacteriostatic zone was measured by crossover method. The antibacterial activity of the tested solutions was evaluated by the diameter of the bacteriostatic zone (A) and the bacteriostatic rate $(\mathrm{R})$, as shown in formula (7).

$$
R=\frac{\mathrm{A}-\mathrm{C}}{\mathrm{B}-\mathrm{C}} \times 100 \%
$$

In the formula, $\mathrm{R}$ is the bacteriostasis rate (\%); $\mathrm{A}$ is the diameter/mm of the bacteriostasis circle of the ETFQ; $B$ is the diameter/mm of the bacteriostasis circle of the potassium sorbate; and $\mathrm{c}$ is the diameter/mm of the hole formed by Oxford cup.

\section{Results}

\section{Effect of system composition of ATPEs on quinoa flavonoids extraction}

The effect of system composition on flavonoids was studied by single factor. In a certain range, the extraction rate of flavonoids increased with the concentration of ethanol and ammonium sulfate in the aqueous two-phase system (Fig. 1). The extraction rate of TFQ gradually increased with the increase of ethanol volume fraction (Fig. 1A) and the mass fraction of $\left(\mathrm{NH}_{4}\right)_{2} \mathrm{SO}_{4}$ (Fig. 1B). When the volume fraction of ethanol reached $28 \%$ and the mass fraction of $\left(\mathrm{NH}_{4}\right)_{2} \mathrm{SO}_{4}$ was $14 \%$, the TFQ extraction rate and the partition coefficient all reached the maximum. When the volume fraction of ethanol is more than $28 \%$ and the mass fraction of $\left(\mathrm{NH}_{4}\right)_{2} \mathrm{SO}_{4}$ is higher than $14 \%$, both the extraction rate and the partition coefficient decreased. Thus, the composition of the two aqueous phase system for TFQ extraction is $14 \%\left(\mathrm{NH}_{4}\right)_{2} \mathrm{SO}_{4}+28 \% \mathrm{C}_{2} \mathrm{H}_{5} \mathrm{OH}$.

\section{Factors affecting TFQ extraction in aqueous two-phase system}

The results show that the main factors affecting the extraction efficiency of the quinoa flavonoids are the concentration of the feed solution, the $\mathrm{pH}$ of the system and the concentration of inorganic salts.

In the $28 \% \quad \mathrm{C}_{2} \mathrm{H}_{5} \mathrm{OH}-14 \%\left(\mathrm{NH}_{4}\right)_{2} \mathrm{SO}_{4}$ aqueous twophase extraction system, it showed that the extraction rate of TFQ increased with the increase of crude flavonoids volume fraction (Fig. 2A). The mass fraction of crude extract affects the extraction rate and partition coefficient of $\mathrm{C}_{2} \mathrm{H}_{5} \mathrm{OH}-$ $\left(\mathrm{NH}_{4}\right)_{2} \mathrm{SO}_{4}$ aqueous two-phase system. When the mass fraction of crude extract increased, both the extraction rate and the partition coefficient showed similar trends. When the mass fraction of crude extract was $18 \%$, the two values reach the maximum $(77.2 \%$ and 0.617 , respectively). Then the extraction rate and the distribution coefficient gradually decreased.

When the $\mathrm{pH}<7$, the distribution coefficient and extraction rate increased gradually with the increasing $\mathrm{pH}$ (Fig. 2B). When the $\mathrm{pH}$ was 7 , the distribution coefficient and the extraction rate reached the maximum. When the $\mathrm{pH}>7$, namely alkaline condition, the distribution coefficient and the extraction rate decreased with the increase of the $\mathrm{pH}$.

Results showed that with the increase of mass fraction of $\mathrm{NaCl}$ in the extraction system (Fig. 2C), the partition coefficient and the extraction rate showed the same trend. When the mass fraction of $\mathrm{NaCl}$ was $2.5 \%$, the two parameters reached the maximum. Therefore, the mass fraction of $\mathrm{NaCl}$ in the extraction system was selected as $2.5 \%$.

\section{Optimization of TFQ extraction by response surface method}

The establishment and analysis of mathematical model: The response surface modeling test of TFQ yield was carried out by using Design-Expert 8.0.6 on three factors of crude extract mass fraction (A), $\mathrm{NaCl}(\mathrm{B})$ and $\mathrm{pH}(\mathrm{C})$. The design of the factor level and the result of the center combination are shown in Table 1.

With the TFQ extraction rate as the response value, the mathematical model equation of the three influencing factors was obtained through the Design Expert 8.0.6 by regression of the three influencing factors. The variance analysis of the mathematical model (Table 2) showed that the regression model was very significant $(P=0.0043<$ $0.01)$, and the lack of fit was not significant $(P=0.7042)$. It showed that the unknown factor has little effect on the TFQ yield, and the model fitting effect was good. The variance analysis of the model showed that A (crude extract) had a significant effect on the extraction rate, while $\mathrm{B}(\mathrm{NaCl})$ and $\mathrm{C}(\mathrm{pH})$ had no significance. The effect of each factor on TFQ extraction rate was in the order of A (Crude extract) > $\mathrm{C}(\mathrm{pH})>\mathrm{B}(\mathrm{NaCl})$ mass fraction. By regression model fitting, the influence of three factors on response value $Y$ (TFQ extraction rate) can be expressed by the following multiple quadratic equation: Extraction rate $=74.28+1.78$ $\mathrm{A}+0.10 \mathrm{~B}+0.38 \mathrm{C}+0.20 \mathrm{AB}+0.050 \mathrm{AC}+0.050 \mathrm{BC}+1.000 \mathrm{E}-$ $002 \mathrm{~A}^{2}-0.94 \mathrm{~B}^{2}-0.69 \mathrm{C}^{2}$.

Interaction response surface of various factors and optimal validation: As shown in the Fig. 3, the response surface of extraction rate opens downward, and the three restrictive factors on extraction rate and aqueous two-phase extraction system show an obvious quadratic parabolic relationship. With the increase of each factor level, the extraction rate of response value also increased. According to the theory of extraction kinetics, with the increase of three 
Enhanced Extraction Efficiency and Improvement the Flavonoid Activity / Intl J Agric Biol, Vol 25, No 6, 2021

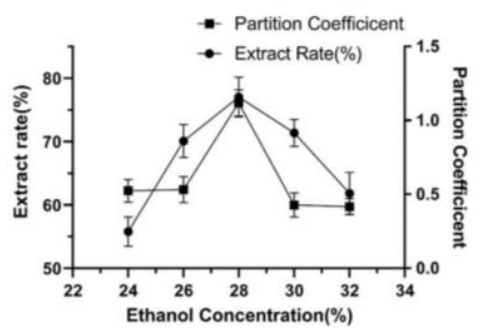

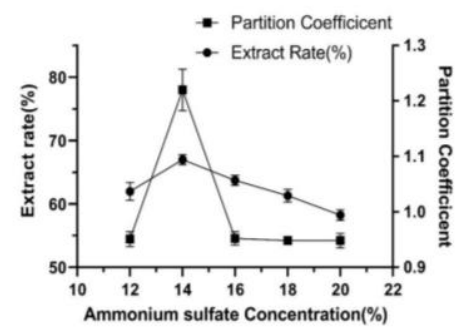

B

Fig. 1: Effect of system composition of ATPEs on quinoa flavonoids extraction
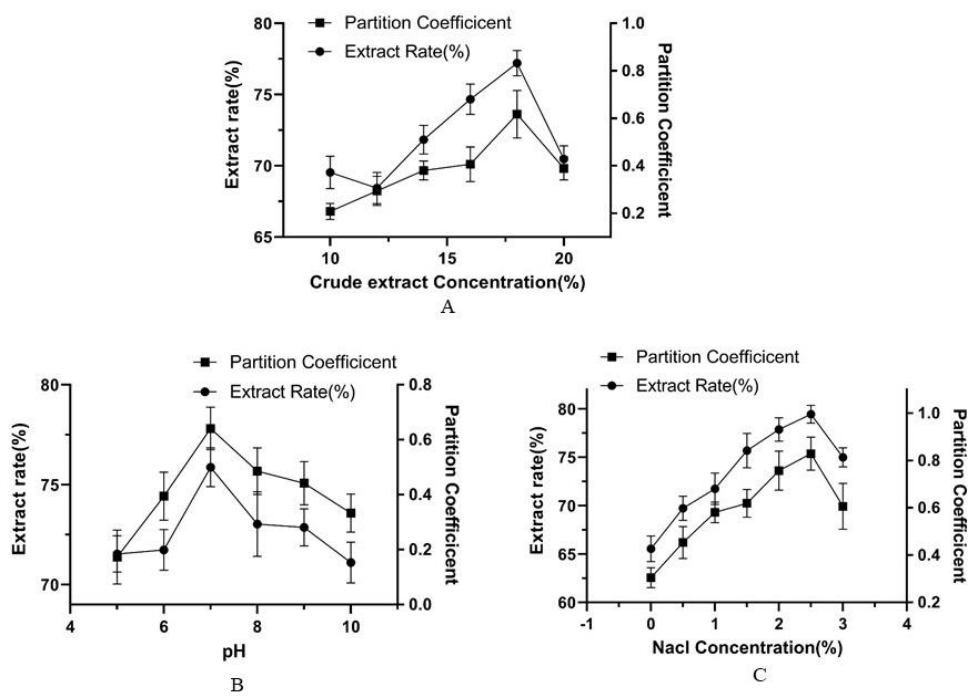

Fig. 2: Factors affecting TFQ extraction in aqueous two-phase system
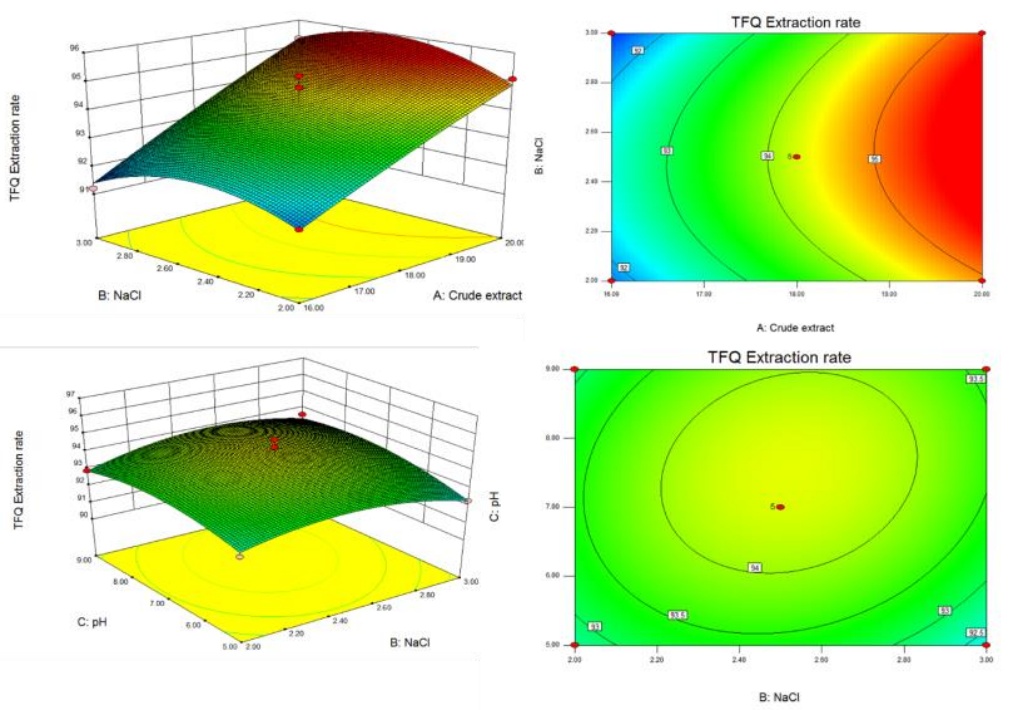

Fig. 3: The interaction effects of three factors on extraction rate of TFQ

factors, the extraction rate of response value reaches its maximum and then decreases with the increase of three factors. The regression model has a stable point and a stable point is the maximum. The extraction rate of TFQ was estimated by means of the multiple quadratic regression model, and the extremum value of the quadratic parabolic function model was analyzed. The best combination coordinates $\mathrm{Z}(1,0.29,0.31)$ of the three factors was 
Wu et al. / Intl J Agric Biol, Vol 25, No 6, 2021

Table 1: Arrangement and results of response surface methodology

\begin{tabular}{lcccc}
\hline Test number & A: Crude extract $(\%)$ & $\mathrm{B}: \mathrm{NaCl}(\%)$ & $\mathrm{C}: \mathrm{pH}$ & TFQ Extraction rate $(\%)$ \\
\hline 1 & 16 & 2.0 & 7 & 71.8 \\
2 & 18 & 3.0 & 9 & 73.6 \\
3 & 20 & 3.0 & 7 & 75.3 \\
4 & 20 & 2.5 & 5 & 75.2 \\
5 & 18 & 2.5 & 7 & 75.5 \\
6 & 20 & 2.5 & 9 & 74.8 \\
7 & 18 & 2.5 & 7 & 73.7 \\
8 & 18 & 2.5 & 7 & 72.3 \\
9 & 18 & 3.0 & 5 & 72.9 \\
10 & 18 & 2.0 & 9 & 75.1 \\
11 & 20 & 2.0 & 7 & 73.5 \\
12 & 18 & 2.5 & 7 & 71.2 \\
13 & 16 & 3.0 & 7 & 72.0 \\
14 & 16 & 2.5 & 5 & 74.2 \\
16 & 16 & 2.5 & 9 & 7.8 \\
\hline
\end{tabular}

Table 2: ANOVA for Response Surface Quadratic Model for TFQ

\begin{tabular}{|c|c|c|c|c|c|}
\hline Source & Sum of Squares & df & Mean Square & F-Value & p-Value \\
\hline Model & 32.646706 & 9 & 3.627412 & 8.947104 & 0.0043 significant \\
\hline A-Crude extract & 25.205 & 1 & 25.205 & 62.16878 & $<0.0001$ \\
\hline $\mathrm{B}-\mathrm{NaCl}$ & $8.00 \mathrm{E}-02$ & 1 & $8.00 \mathrm{E}-02$ & $1.97 \mathrm{E}-01$ & 0.6703 \\
\hline C-pH & 1.125 & 1 & 1.125 & 2.774841 & 0.1397 \\
\hline $\mathrm{AB}$ & 0.16 & 1 & 0.16 & 0.394644 & 0.5498 \\
\hline $\mathrm{AC}$ & 0.01 & 1 & 0.01 & 0.024665 & 0.8796 \\
\hline $\mathrm{BC}$ & 0.01 & 1 & 0.01 & 0.024665 & 0.8796 \\
\hline$A^{2}$ & 0.0004211 & 1 & 0.000421 & 0.001039 & 0.9752 \\
\hline $\mathrm{B}^{2}$ & 3.7204211 & 1 & 3.720421 & 9.176514 & 0.0191 \\
\hline $\mathrm{C}^{2}$ & 2.0046316 & 1 & 2.004632 & 4.944475 & 0.0615 \\
\hline Residual & 2.838 & 7 & 0.405429 & & \\
\hline Lack of Fit & 0.77 & 3 & 0.256667 & 0.496454 & 0.7042 not significant \\
\hline Pure Error & 2.068 & 4 & 0.517 & & \\
\hline Cor Total & 35.484706 & 16 & & & \\
\hline
\end{tabular}

predicted, that is, the mass fraction of crude extract was $20.6 \%, \mathrm{pH} 7.18, \mathrm{NaCl} 2.23 \%$. Under these conditions, the maximum value of the model was $\mathrm{Y}=75.9293 \%(P=$ 0.994). Three groups of repeated experiments were carried out in the $\mathrm{Z}$ coordinate. The average extraction rate of TFQ reached $75.3 \%$. The results showed that the regression model can accurately predict TFQ extracted by the aqueous two-phase system.

\section{Evaluation of antioxidant in vitro of the ETFQ}

Scavenging of hydroxyl radical: The hydroxyl radical belongs to a kind of strong oxidant, and the most active oxygen molecule in the organism. Thus, it is highly destructive (Sander et al. 2014). It can react with almost any biological molecule in a living cell to cause damage. Therefore, the elimination of excessive $\cdot \mathrm{OH}$ in the body has a very important biological significance. As shown in Fig. $4 \mathrm{~A}$, with the increase in mass concentration, the clearance rates of sample solution and vitamin $\mathrm{C}$ to $\cdot \mathrm{OH}$ increased. When the concentration of ETFQ in the test solution was $0.3 \mathrm{~g} / \mathrm{L}$, the clearance rate of $\mathrm{OH}$ was $94.63 \%$. When the mass concentration of vitamin $\mathrm{C}$ was $0.6 \mathrm{~g} / \mathrm{L}$, the clearance rate of $\cdot \mathrm{OH}$ was $39.9 \%$. Therefore, the ETFQ has a strong scavenging effect on $\cdot \mathrm{OH}$ and its scavenging ability is significantly higher than that of vitamin $\mathrm{C}$.

Scavenging of oxygen free radicals: Superoxide anion can generate other oxygen free radicals through a series of reactions. It can attack cell DNA, and it has high toxicity (Janik and Tripathi 2013). Therefore, it is important to eliminate the excessive $\mathrm{O}_{2}{ }^{-}$. in biological organisms. It was shown from Fig. 4B, with the increase in mass concentration, the clearance rates of $\mathrm{O}_{2}^{-}$of the ETFQ and vitamin $\mathrm{C}$ increase gradually. When the concentration of ETFQ was 0.1 and $0.6 \mathrm{~g} / \mathrm{L}$, the scavenging rate of $\mathrm{O}_{2}{ }^{-}$was 88.64 and $96.93 \%$, respectively, while the clearance rate for $\mathrm{O}_{2}{ }^{-}$was only $22.31 \%$ when the vitamin $\mathrm{C}$ concentration was $0.1 \mathrm{~g} / \mathrm{L}$. The results show that the test solution has strong scavenging capacity for $\mathrm{O}_{2}^{-}$, and its scavenging ability is higher than vitamin $\mathrm{C}$ at low concentration.

Scavenging of nitrite: Excessive nitrite can affect the functioning of red blood cells, making it impossible for the blood to carry oxygen. In severe cases, the brain is deprived of oxygen and may even die (Fisher et al. 2017). Fig. 4C 


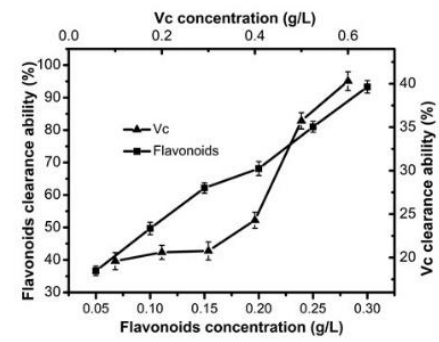

A

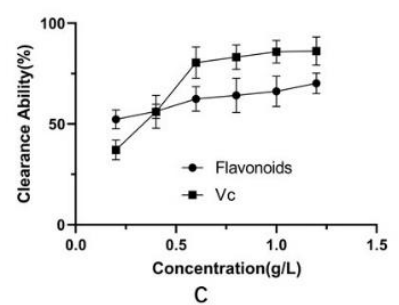

C

Fig. 4: The antioxidant activity of the ETFQ in vitro

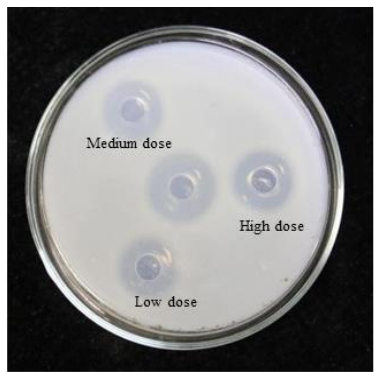

S.aureus

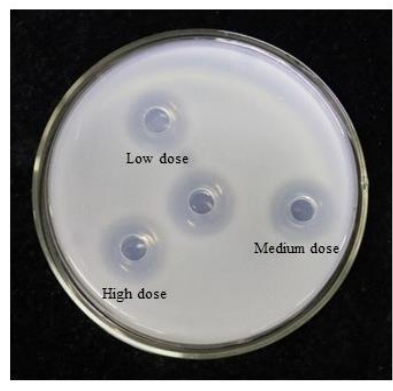

E.coli

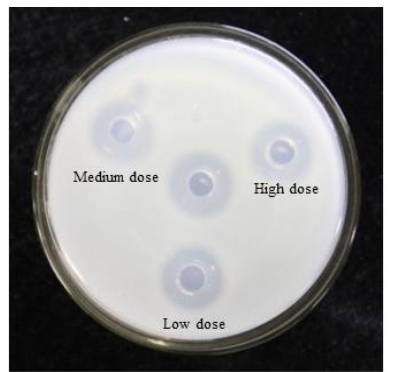

Bacillus subtilis

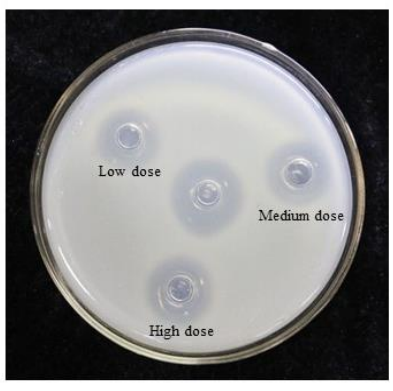

Salmonella
Fig. 5: The bacteriostasis diameter and bacteriostasis rate of ETFQ

shows that with increasing concentration and volume, the clearance of $\mathrm{NaNO}_{2}$ by the flavonoids solution and vitamin $\mathrm{C}$ increased gradually. When the concentration of ETFQ was $1 \mathrm{~g} / \mathrm{L}$ and the volume was $1.2 \mathrm{~mL}$, the scavenging rate of $\mathrm{NaNO}_{2}$ was $66.34 \%$, while the clearance rate of $\mathrm{NaNO}_{2}$ was up to $84.92 \%$ when the concentration of vitamin $\mathrm{C}$ was $0.1 \mathrm{~g} / \mathrm{L}$ and the volume was $1.2 \mathrm{~mL}$. The results show that the ETFQ had a certain scavenging effect on $\mathrm{NaNO}_{2}$, but its scavenging ability was weaker than vitamin $\mathrm{C}$.

Scavenging of $\cdot \mathbf{A B T S}^{+}$: ABTS can be oxidized to green $\mathrm{ABTS}^{+}$with proper oxidant, and the production of ABTS is restrained when the antioxidant is present (Bora et al. 2019).
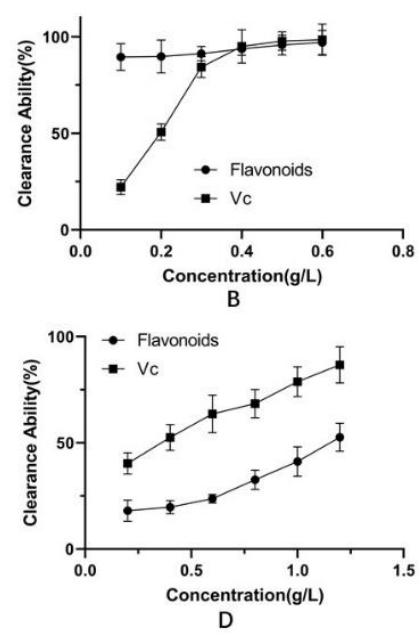

The total antioxidant capacity of the sample can be determined by measuring the absorbance of ABTS. With the increase in concentration, the scavenging rate of -ABTS+ of the ETFQ and vitamin C increased gradually. When the concentration of ETFQ was $1.2 \mathrm{~g} / \mathrm{L}$, the scavenging rate of $\cdot \mathrm{ABTS}^{+}$was up to $87.24 \%$, while the clearance rate of vitamin $\mathrm{C}$ was only $52.58 \%$ (Fig. 4D). The results show that the ETFQ has strong scavenging effects on $\mathrm{ABTS}^{+}$and its scavenging ability is significantly higher than that of vitamin $\mathrm{C}$.

Minimum inhibitory concentration (MIC) and minimum bactericidal concentration (MBC)

As shown in Table 3, the MIC of ETFQ for Bacillus subtilis ACCC 01430 and E. coli is $1.56 \mathrm{mg} / \mathrm{mL}$. The MIC of ETFQ for $S$. aureus ACCC01332 is $6.25 \mathrm{mg} / \mathrm{mL}$ and for Salmonella ACCC01319 is $12.50 \mathrm{mg} / \mathrm{mL}$. The results show that ETFQ has the strongest inhibitory activity against Bacillus subtilis ACCC01430 and E. coli; Salmonella ACCC01319 exhibited a strong tolerance to the ETFQ.

\section{In vitro bacteriostasis diameter and bacteriostasis rate of ETFQ}

As shown in Table 4, ETFQ showed good bacteriostatic activity to all four tested strains, and the tolerance of four tested strains to ETFQ was significantly different among individuals. The diameter of the bacteriostasis circle (Fig. 5) of Bacillus subtilis and E. coli was $16.64 \pm 0.12 \mathrm{~mm}$ and $14.28 \pm 0.13 \mathrm{~mm}$, respectively, under high dosage. The results were similar to that of the control potassium sorbate. The bacteriostasis rate were 98.44 and $97.59 \%$, respectively. This indicated that the bacteriostasis circle had a strong inhibition on the mycelial growth of Bacillus subtilis ACCC01430 and E. coli ACCC11864, followed by $S$. 
Wu et al. / Intl J Agric Biol, Vol 25, No 6, 2021

Table 3: MIC and MBC of ETFQ

\begin{tabular}{|c|c|c|c|c|c|c|c|c|c|c|c|}
\hline \multirow[t]{2}{*}{ Strains } & \multicolumn{10}{|c|}{$\mathrm{MIC}(\mathrm{mg} / \mathrm{mL})$} & \multirow[t]{2}{*}{$\mathrm{MBC}(\mathrm{mg} / \mathrm{mL})$} \\
\hline & 0 & 0.2 & 0.39 & 0.78 & 1.56 & 3.12 & 6.25 & 12.5 & 25 & 50 & \\
\hline E.coli ACCC11864 & - & - & - & - & + & + & + & + & + & + & 3.12 \\
\hline S.aureus ACCC01332 & - & - & - & - & - & - & + & + & + & + & 12.5 \\
\hline Salmonella ACCC01319 & - & - & - & - & - & - & - & + & + & + & 25 \\
\hline Bacillus subtilis ACCC 01430 & - & - & - & - & + & + & + & + & + & + & 3.12 \\
\hline
\end{tabular}

Table 4: Diameter of inhibition zone and bacteriostasis rate of testing strains exposed to ETFQ

\begin{tabular}{|c|c|c|c|c|c|c|c|c|}
\hline \multirow[t]{2}{*}{ Strains } & \multicolumn{5}{|c|}{ Diameter of inhibition zone (mm) } & \multicolumn{3}{|c|}{ Inhibition rate $(\%)$} \\
\hline & Blank (mm) & Potassium sorbate $(0.5 \%)$ & Low dose & Medium dose & High dose & Low dose & Medium dose & High dose \\
\hline$\overline{E . c o l i ~ A C C C 11864 ~}$ & $7.80 \pm 0.00$ & $14.44 \pm 0.31$ & $13.08 \pm 0.31$ & $13.45 \pm 0.04$ & $14.28 \pm 0.13$ & 79.51 & 85.09 & 97.59 \\
\hline S.aureus ACCC01332 & $7.80 \pm 0.00$ & $18.91 \pm 0.35$ & $15.71 \pm 0.43$ & $16.64 \pm 0.33$ & $17.37 \pm 0.72$ & 71.20 & 79.57 & 86.14 \\
\hline Bacillus subtilis ACCC01430 & $7.80 \pm 0.00$ & $16.78 \pm 0.04$ & $15.90 \pm 0.11$ & $16.21 \pm 0.02$ & $16.64 \pm 0.12$ & 91.11 & 94.6 & 98.44 \\
\hline Salmonella ACCC01319 & $7.80 \pm 0.00$ & $17.11 \pm 0.11$ & $13.21 \pm 0.42$ & $13.45 \pm 0.37$ & $13.82 \pm 0.58$ & 54.26 & 56.67 & 60.38 \\
\hline
\end{tabular}

aureus ACCC01332 and Salmonella ACCC01319. In a word, the diameter of the bacteriostasis circle of the tested bacteria increased with increasing ETFQ concentration, and the bacteriostasis rate is positively correlated with the concentration of ETFQ.

\section{Discussion}

Different solvents were found to have different extraction efficiencies for flavonoids, which exhibited high levels of antioxidant activity. In the aqueous two-phase extraction system composed of ethanol and ammonium sulfate, the environment formed by ethanol and water is favorable for the dissolution of flavonoids. The presence of ammonium sulfate can adjust the charge distribution of the extraction system ( $\mathrm{Li}$ et al. 2010), which is beneficial to the extraction of flavonoids, and the trace amounts of protein in the crude extract can be removed by salting-out of ammonium sulfate. Meanwhile, aqueous two-phase systems are easily scalable and conditions can be controlled, making them suitable for industrial-scale production.

Flavonoids are bioactive compounds that are found in the form of pigments in plant parts, such as fruits and flowers (Carciochi et al. 2015). These are synthesized by plants as a response to environmental stress and microbial infections, and are known to have antioxidant, antiinflammatory and also antimicrobial properties, especially their free radical-scavenging ability (Kalogeropoulos et al. 2009). Antioxidant activity is largely attributable to the amount of phenolic compounds, including flavonoids, especially in the dark color quinoa seeds (Hirose et al. 2010).

In this study, the ETFQ showed different degree of clearance ability to four kinds of free radicals, as shown in Fig. 4. There is a good correlation between the ETFQ contents and the radical-scavenging abilities, except for nitrite. The predominant flavonoids in quinoa samples were quercetin and kaempferol while in some varieties myricetin and isorhamnetin were also found. The dark color seeds may contain mostly quercetin and isorhamnetin with smaller amounts of myricetin, kaempferol and rhamnetin (RepoCarrasco-Valencia et al. 2010). Thus, the ETFQ showed a broad spectrum of antimicrobial activity against grampositive and gram-negative bacteria might due to the high content of quercetin and isorhamnetin. Similarly, (Zeng et al. 2011) working with water-soluble extract from pine needles, which is rich in flavonoids, have activity against microorganisms. The antimicrobial activity was present in the ETFQ might explain its broad-spectrum activity against microorganisms (Fig. 5). Similar observations were reported (Shan et al. 2007) regarding the correlation between total flavonoids and the antibacterial activity of various plant extracts.

Although ETFQ showed good bacteriostatic activity against four strains of testing bacteria, especially Bacillus subtilis and E. coli, the specific components of flavonoids that play an antibacterial role cannot be determined in this paper. Flavonoids generally refer to a series of compounds in which two benzene rings (A- and B-rings) with phenolic hydroxyl groups are connected to each other through a central three-carbon atom. The basic core is 2phenylchromogen. Subsequent in-depth research should be conducted on ETFQ and the specific antibacterial flavonoid components should be identified. Additionally, the mechanisms of how ETFQ affects Gram-negative and positive bacteria require further study.

\section{Conclusion}

Quinoa flavonoids are a kind of food flavone, which has the unique resource advantage of being developed into natural functional foods. Aqueous two-phase system significantly improved the antioxidant and antibacterial properties of quinoa flavonoids. This experiment can also carry out further in-depth research: structural identification and physiological activity experiments on quinoa flavonoids to 
obtain products with known structure and function, so that to develop the medicinal value of quinoa as much as possible and to increase its economic value.

\section{Acknowledgements}

We thank Professor Jianglin Zhao and Sichuan Industrial Institute of Antibiotics of Chengdu University for the experimental strains. We thank LetPub (www.letpub.com) for its linguistic assistance during the preparation of this manuscript.

\section{Author Contributions}

Xiaoyong Wu and Yanxia Sun conceived and designed the experiments; Enze Liu, Yan Wan and Qi Wu performed the experiments; Dabing Xiang and Changying Liu analyzed the data; Xiaoyong $\mathrm{Wu}$ and Enze Liu wrote the paper; Yanxia Sun reviewed the manuscript.

\section{Conflict of Interest}

The authors declare no conflict of interest.

\section{Data Availability}

All data, models, and code generated or used during the study appear in the submitted article.

\section{Ethics Approval}

All studies involving animals were reviewed and approved by the Institutional Animal Care and Use Committee of Hebei Normal University of Science and Technology, China. Procedures were performed in accordance with the Regulations for the Administration of Affairs Concerning Experimental Animals (The State Council of the People's Republic of China, 2011). Animals were humanely sacrificed as necessary to ameliorate suffering.

\section{References}

Abe O, S Misaka, H Sato, H Ogata, T Ono, Y Shikama, S Onoue, H Yabe, J Kimura (2017). Effect of epigallocatechin gallate on pharmacokinetics of NADOLOL in healthy volunteers. Clin Ther 39; Article e31

Abotaleb M, SM Samuel, E Varghese, S Varghese, P Kubatka, A Liskova, D Büsselberg (2019). Flavonoids in cancer and apoptosis. Cancers 11:28-36

Angeli V, P Miguel Silva, D Crispim Massuela, MW Khan, A Hamar, F Khajehei, S Graeff-Honninger, C Piatti (2020). Quinoa (Chenopodium quinoa Willd.): An overview of the potentials of the "Golden Grain" and socio-economic and environmental aspects of its cultivation and marketization. Foods 9:216-246

Assis RC, AB Mageste, LR de Lemos, RM Orlando, GD Rodrigues (2020). Application of aqueous two-phase systems for the extraction of pharmaceutical compounds from water samples. J Mol Liq 301:1-9

Bellemare MF, J Fajardo Gonzalez, SR Gitter (2018). Foods and fads: The welfareimpacts of rising quinoaprices in Peru. World Dev 112:163-179
Bohn SK, NC Ward, JM Hodgson, KD Croft (2012). Effects of tea and coffee on cardiovascular disease risk. Food Funct 3:575-591

Bora G, D Gogoi, S Saikia, A Pareek, JG Handique (2019). Stannous chloride catalyzed synthesis of Schiff bases from hydroxybenzaldehydes and determination of their antioxidant activity by ABTS and DPPH assay. J Chem Sci 131:68-76

Brend Y, L Galili, H Badani, R Hovav, S Galili (2012). Total phenolic content and antioxidant activity of red and yellow quinoa seeds as affected by baking and cooking conditions. Food Nutr Sci 3:1150-1155

Carciochi RA, GD Manrique, K Dimitrov (2015). Optimization of antioxidant phenolic compounds extraction from quinoa (Chenopodium quinoa) seeds. J Food Sci Technol 52:4396-4404

Sezgin AC, N Sanlier (2019). A new generation plant for the conventional cuisine: Quinoa (Chenopodium quinoa Willd.). Trends Food Sci Technol 86:51-58

Dakhili S, L Abdolalizadeh, SM Hosseini, S Shojaee-Aliabadi, L Mirmoghtadaie (2019). Quinoa protein: Composition, structure and functional properties. Food Chem 299:1-10

Dini I, GC Tenore, A Dini (2010). Antioxidant compound contents and antioxidant activity before and after cooking in sweet and bitter Chenopodium quinoa seeds. LWT-Food Sci Technol 43:447-451

Filho AM, MR Pirozi, JT Borges, HM Pinheiro Sant'Ana, JB Chaves, JS Coimbra (2017). Quinoa: Nutritional, functional, and antinutritional aspects. Crit Rev Food Sci Nutr 57:1618-1630

Fisher DR, SM Poulose, DF Bielinski, B Shukitt-Hale (2017). Serum metabolites from walnut-fed aged rats attenuate stress-induced neurotoxicity in BV-2 microglial cells. Nutr Neurosci 20:103-109

Garai D, V Kumar (2013). Aqueous two-phase extraction of alkaline fungal xylanase in PEG/phosphate system: Optimization by Box-Behnken design approach. Biocatalysis Agric Biotechnol 2:125-131

Gu Z, CE Glatz (2007). Aqueous two-phase extraction for protein recovery from corn extracts. J Chromatogr B Anal Technol Biomed Life Sci 845:38-50

Hemalatha P, DP Bomzan, BV Sathyendra Rao, YN Sreerama (2016). Distribution of phenolic antioxidants in whole and milled fractions of quinoa and their inhibitory effects on alpha-amylase and alphaglucosidase activities. Food Chem 199:330-338

Huang Y, D Chen, L Kong, M Su, Y Chen (2020). Aqueous two-phase systems (polyethylene glycol+ammonia sulfate)forthallium extraction: Optimization of extraction efficiency, structural characterization, and mechanism exploration. Sep Purif Technol 235; Article 115740

Janik I, GNR Tripathi (2013). The nature of the superoxide radical anion in water. J Chem Phys 139:14302-14307

Kalogeropoulos N, SJ Konteles, E Troullidou, I Mourtzinos, VT Karathanos (2009) Chemical composition, antioxidant activity and antimicrobial properties of propolis extracts from Greece and Cyprus. Food Chem $116: 452-461$

Lavanya V, D Ganapathy, RM Visalakshi (2019). Flavonoids used in the treatment of malignancy - A review. Drug Invention Today 12:1082-1085

Lee SY, I Khoiroh, CW Ooi, TC Ling, PL Show (2017). Recent advances in protein extraction using ionic liquid-based aqueous two-phase systems. Sep Purif Rev 46:291-304

Li Z, H Teng, Z Xiu (2010). Aqueous two-phase extraction of 2,3butanediol from fermentation broths using an ethanol/ammonium sulfate system. Process Biochem 45:731-737

Lopez DN, M Galante, M Robson, V Boeris, D Spelzini (2018). Amaranth, quinoa and chia protein isolates: Physicochemical and structural properties. Intl J Biol Macromol 109:152-159

Navruz-Varli S, N Sanlier (2016). Nutritional and health benefits of quinoa (Chenopodium quinoa Willd.). J Cereal Sci 69:371-376

Orfali G, AC Duarte, V Bonadio, NP Martinez, ME de Araujo, FB Priviero, PO Carvalho, DG Priolli (2016). Review of anticancer mechanisms of isoquercitin. World J Clin Oncol 7:189-199

Penido AB, SM De Morais, AB Ribeiro, DR Alves, AL Rodrigues, LH Dos Santos, JE de Menezes (2017). Medicinal plants from Northeastern Brazil against Alzheimer's disease. Evid-Based Compl Alt 2017; Article 1753673

Perez Vizcaino F, CG Fraga (2018). Research trends in flavonoids and health. Arch Biochem Biophys 646:107-112 
Rai S, A Kaur, CS Chopra (2018). Gluten-free products for celiac susceptible people. Front Nutr 5:1-23

Repo-Carrasco-Valencia R, JK Hellström, JM Pihlava, PH Mattila (2010). Flavonoids and other phenolic compounds in Andean indigenous grains: Quinoa (Chenopodium quinoa), kañiwa (Chenopodium pallidicaule) and kiwicha (Amaranthus caudatus). Food Chem 120:128-133

Romano N, MM Ureta, M Guerrero-Sanchez, A Gomez-Zavaglia (2020). Nutritional and technological properties of a quinoa (Chenopodium quinoa Willd.) spray-dried powdered extract. Food Res Intl 129; Article 108884

Ruiz K, S Biondi, R Oses, I Acuña-Rodríguez, F Antognoni, E MartinezMosqueira, A Coulibaly, A Canahua-Murillo, M Pinto, A ZuritaSilva, D Bazile, SE Jacobsen, M Molina-Montenegro (2014). Quinoa biodiversity and sustainability for food security under climate change. A review. Agron Sustain Dev 34:349-359

Sanchez Hernandez D, GH Anderson, AN Poon, E Pannia, CE Cho, PSP Huot, R Kubant (2016). Maternal fat-soluble vitamins, brain development, and regulation of feeding behavior: An overview of research. Nutr Res 36:1045-1054

Sander W, S Roy, K Bravo Rodriguez, D Grote, E Sanchez Garcia (2014). The benzylperoxyl radical as a source of hydroxyl and phenyl radicals. Chemistry 20:12917-12923

Shan B, YZ Cai, J Brooks, H Corke (2007). The in vitro antibacterial activity of dietary species and medicinal herb extracts. Intl $J$ Food Microbiol 117:112-119
Shi G, X Zhang, L Wu, J Xie, K Tao, T Hou (2011). Mutational biosynthesis of neomycin analogs by a mutant of neomycinproducing Streptomyces fradiae. Folia Microbiol 56:555-561

Shkinev V, N Mokshina, V Khokhlov, B Spivakov (2013). Extraction of biologically active compounds in two-phase aqueous systems based on poly- N-vinylpyrrolidone. Dokl Chem 448:49-51

Vilcacundo R, B Hernández-Ledesma (2017). Nutritional and biological value of quinoa (Chenopodium quinoa Willd.). Curr Opin Food Sci $14: 1-6$

Xiang D, C Ma, Y Song, Q Wu, X Wu, Y Sun, G Zhao, Y Wan (2019a). Post-Anthesis photosynthetic properties provide insights into yield potential of Tartary buckwheat cultivars. Agronomy 9; Article 149

Xiang HY, HH Xing, J Li, L Ye, WS Kong, X Liu, YP Li, CQ Jiang, MF Wang, QF Hu, GY Yang, XM Li, ZY Chen (2019b). Two new isoflavones from the flowers of rosa damascena and their biological activities. Chem Nat Comp 55:449-452

Hirose Y, T Fujita, T Ishii, N Ueno (2010). Antioxidative properties and flavonoid composition of Chenopodium quinoa seeds cultivated in Japan. Food Chem 119:1300-1306

Zeng WC, LR Jia, Y Zhang, JQ Cen, X Chen, H Gao, S Feng, YN Huang (2011). Antibrowning and antimicrobial activities of the watersoluble extract from pine needles of Cedrus deodara. J Food Sci 76:C318-C123

Zhu F (2018). Chemical composition and food use of teff (Eragrostis tef). Food Chem 239:402-415 